\title{
OBSERVATIONS ON THERAPEUTIC TRANSFORAMINAL EPIDURAL STEROID INJECTIONS FOR LUMBOSACRAL NERVE ROOT PAIN
}

\author{
Mohd Ahsan Wani' ${ }^{1}$ Akhter Rasool ${ }^{2}$, Nuzhatul Islam $^{3}$, Mudasir Nazir 4 \\ ${ }_{1}^{1}$ Senior Resident, Department of Orthopaedics, GMC, Srinagar, Jammu and Kashmir, India. \\ 2Postgraduate Student, Department of Orthopaedics, GMC, Srinagar, Jammu and Kashmir, India. \\ ${ }^{3}$ Senior Resident, Department of Anaesthesia, GMC, Srinagar, Jammu and Kashmir, India. \\ ${ }^{4}$ Postgraduate Student, Department of Orthopaedics, GMC, Srinagar, Jammu and Kashmir, India.

\section{ABSTRACT}

\section{BACKGROUND}

Low back pain combined with radicular pain is one of the most challenging musculoskeletal problems for therapeutic management with a lifetime prevalence estimated to be around $40 \%$ to $60 \%$. We wanted to observe the results of therapeutic transforaminal epidural steroid injection for lumbosacral nerve root pain with regard to pain relief, patient satisfaction and improvement in return to work status before and after the injection.

\section{METHODS}

This study was conducted in the post-graduate department of orthopaedics, Govt. Hospital for Bone and Joint Surgery, an associated hospital of Govt. Medical College, Srinagar from Sept. 2016 to Sept. 2018. The study consisted of a total of 100 patients. Patient was explained in detail about the Visual Analogue Scale (VAS) and Oswestry Questionnaire.

\section{RESULTS}

A total of 100 patients with $53 \%$ males $47 \%$ females was included in this study. The mean age was 40.3 years. $59 \%$ of patients had right sided radiculopathy and $41 \%$ had it on left side. The average duration of symptoms was 4.13 months with standard deviation of 0.788 . The average pre injection SLR was $59.20^{\circ}$ which increased post injection to an average of $85.35^{\circ}(\mathrm{p}$-value $<0.001) .88$ of the patients had a lateral disc herniation and central prolapse of disc (4\%) on MRI. 42\% received L5 TFESI followed by S1 (40\%). Mean VAS before injection was 5.98 with S.D. of \pm 1.359 . The mean VAS after 6 months was $2.25 \pm 1.316$. Mean pre-injection ODI was 32.95 (S.D. of 8.26). After TFESI, it dropped to 11.91 at 1 week, 12.03 at 4 weeks and increased a bit to 15.63 with S.D. of 5.03. p-value<0.001. $63 \%$ of our patients had excellent outcome, $33 \%$ had good, $3 \%$ had fair and $1 \%$ had poor outcome as measured by modified McNab scale.

\section{CONCLUSIONS}

Transforaminal epidural steroid injection is an effective alternative method of pain control with improvement in disability with excellent patient satisfaction in properly selected patients of lumbosacral radiculopathy.

\section{KEY WORDS}

Transforaminal Epidural Steroid Injection, Low Back Ache, Vas Scale, Intervertebral Disc Herniation

HOW TO CITE THIS ARTICLE: Wani MA, Rasool A, Islam N, et al. Observations on therapeutic transforaminal epidural steroid injections for lumbosacral nerve root pain. J. Evolution Med. Dent. Sci. 2019;8(26):2059-2064, DOI: 10.14260/jemds/2019/454

\section{BACKGROUND}

In modern society, low back pain combined with radicular pain remains as one of the most challenging musculoskeletal problems for therapeutic management with a lifetime prevalence estimated to be around $40 \%$ to $60 \%{ }^{1,2,3}$ Intervertebral disc herniation and degenerative lumbar spinal stenosis are the two most common causes of lumbosacral radiculopathy.4,5,6 Pain from lumbar disk herniation can arise from nerve root compression and stimulation of nociceptors in the annulus or posterior longitudinal ligament. Various proposed mechanisms for radicular pain include partial axonal damage, neuroma formation, and demyelination; intraneural edema; and impaired microcirculation. ${ }^{7}$

'Financial or Other Competing Interest': None.

Submission 07-01-2019, Peer Review 17-05-2019,

Acceptance 22-05-2019, Published 01-07-2019.

Corresponding Author:

Mohd Ahsan Wani,

Resident Doctors Hostel, Karanagar,

Srinagar, Jammu and Kashmir, India.

E-mail: drehsanwani@gmail.com

DOI: $10.14260 /$ jemds/2019/454

\section{(c) $(1) \ominus$}

Methods of treatment for radiculopathy include conservative methods like rest, manipulation, NSAIDS, opioids and surgeries like laminectomy, laminotomy and fenestration procedures. The use of epidural corticosteroid injection for the treatment of axial and radicular back pain was first reported in 1953 by Evan's. ${ }^{8}$ There are three approaches available to access the epidural space for injection purposes i;e., transforaminal, caudal, and interlaminar. Compared with an interlaminar or caudal epidural steroid injection, a transforaminal approach provides minimal risk of dural puncture, better delivery of medication to the site of radiculopathy, and increased spread into the epidural space.7,8,9 Subsequently, only a low volume of medication is necessary to produce the desired effect. ${ }^{10,11,12}$

Currently, TFESI is widely used for the management of lumbosacral radiculopathy. ${ }^{13}$ Injections are made directly into the neural foramen, which is the tip of the ear of "Scottie dog"14 as appears under fluoroscopic guidance just above the opening for the nerve root and outside the epidural space and allows spread of steroid to the anterior epidural space. When the conventional TFESI technique is employed, a spinal needle is positioned within the "Safe Triangle" 15 with the bevel below the inferior aspect of the pedicle 
Steroids have an anti-inflammatory effect, stabilize the neuronal membranes, suppress ectopic discharge within sensitized dorsal root ganglion nerve and have a direct effect on C-fibres. Triamcinolone acetonide is long acting corticosteroid similar anti-inflammatory potency as methylprednisolone. However, no sodium retention effect. It is available in single-use ampoules without preservatives and is cheaper than methylprednisolone. It is less soluble and remains in suspension for longer periods at the injection site as compared to methylprednisolone and this has been proposed as a reason for increased local effect.

\section{Aims and Objectives}

To assess the results of therapeutic transforaminal epidural steriod injection for lumbosacral nerve root pain with regard to Pain relief, Patient satisfaction and improvement in return to work status before and after the injection,

\section{METHODS}

This study was a prospective study conducted in Postgraduate department of Orthopedics, Govt. Hospital for Bone and Joint surgery, an associated hospital of Govt. Medical College, Srinagar from Sept. 2016 to Sept. 2018. The study consisted of a total of 100 patients (both sexes). Sample size taken randomly. A written informed consent was taken from each patient after properly explaining the procedure in detail, its reported benefits and potential complications. A detailed clinical history and thorough general physical examination and local examination including neurological examination of the lower limbs was done on each patient. Patient was explained in detail about the Visual Analogue Scale (VAS) and Oswestry Questionnaire.

\section{Inclusion Criteria}

Age $>18$ years (Either gender), low back ache with radiation of pain along a radicular distribution for at least three months, failed conservative therapy for at least 3 months MRI documented disc herniation, Correlation between the clinically determined level of radiculopathy and the MRI findings, Symptoms suggestive of sensory impairment in the affected limb.

\section{Exclusion Criteria}

Multilevel degenerative spine disease; spondylolisthesis, spondylolysis, Motor deficit(any grade), arachnoiditis, cauda equina syndrome, Previous lumbar spine surgery, Central spinal canal stenosis or foraminal stenosis from other origins, Myelographic contrast allergy, and local anesthetic allergy, History of psychiatric illness or history of substance abuse, Pregnancy, Poorly controlled hypertension and Poorly controlled diabetes (HbA1c>7), Morbid obesity.

Before the procedure, all the patients underwent radiographs of LS spine (AP and lateral views) and MRI LS spine. Baseline blood investigations were done in each patient. Diabetic patients were asked to get a fasting blood sugar profile done on the morning of procedure to assess the glycaemic control as the procedure may cause transient hyperglycaemia.

\section{Procedure Preparation}

Proper informed consent was taken from each patient, a peripheral line using an $18 \mathrm{G}$ cannula was secured in the patients. All procedures were performed in our OT with monitors attached (NIBP, $\mathrm{SpO}_{2}$, ECG), resuscitation equipment ready, the patient in prone position (With a pillow underneath lower abdomen) and under fluoroscopic guidance. The area was prepared by povidone iodine and draped free. Under all aseptic precautions, the skin overlying the target area was anaesthetized with $2 \mathrm{ml}$ of $1 \%$ lidocaine. The level of the epidural injection chosen depended on magnetic resonance imaging (MRI) findings and physical examination. Under fluoroscopy guidance, a 22-gauge needle was then advanced until contact was made with the lower edge of superior transverse process near its junction with superior articular process. The needle was retracted 1-2 $\mathrm{mm}$ and directed towards 6 o'clock position of the appropriate pedicle. The Carm was then adjusted to lateral position to confirm needle position. This radiological position of the needle tip corresponds to the 'safe triangle' in the sub-pedicular area. 1 $\mathrm{ml}$ of iohexol was injected to produce perineurosheathogram. (Demonstrated in photographic section of this study). After adequate dye pattern is obtained, a $2 \mathrm{ml}$ volume containing 1 $\mathrm{ml}$ of triamcinolone and $1 \mathrm{ml}$ of $2 \%$ preservative free lignocaine was injected.

FOR S1 ROOT, C-arm fluoroscopic beam would be directed in cephalocaudal and lateral to medial direction

The spinal needle was advanced in the same way as above until contact is made with sacral bone slightly lateral and inferior to S1 pedicle.

The needle was then walked off the sacrum and placed into the posterior S1 foramen to the medial edge of pedicle.

The C-arm was adjusted to lateral position to confirm position.

The dye and medication were then injected in the same way as above.

\section{Post Procedure}

After the completion of the procedure, the patient was transferred to the recovery area. The patient was assessed for pain relief and any motor or sensory deficit immediately and then $1 \mathrm{hr}$ after the procedure. 1 hour after the procedure the patients were assessed with special emphasis on any complaint, pain relief, SLR, VAS, any complication.

Patient was discharged from the recovery area, 2 to 3 hours post procedure, after having met the following discharge criteria-

1. The patient should be able to walk unaided.

2. The patient should be able to void his/her bladder without any difficulty. After the procedure, the patient was kept resting in the recovery area for 2 to hours. On occasion, patients may feel numb or have a slightly weak or odd feeling in their back or legs for a few hours after the injection. The patient was asked to discuss any immediate pain relief, and any questions or concerns.

\section{Instructions at Discharge}

- Avoid doing any strenuous activities for 24 hours.

- The patient should not drive for 24 hours after the procedure.

- To report any untoward incident.

- Oral antibiotics for 3 days. 
RESULTS

\begin{tabular}{|c|c|c|}
\hline Age Group (Years) & No. of Patients & Percentage \% \\
\hline $20-30$ & 24 & 24 \\
\hline $31-40$ & 27 & 27 \\
\hline $41-50$ & 29 & 29 \\
\hline $51-60$ & 20 & 20 \\
\hline Total & $\mathbf{1 0 0}$ & $\mathbf{1 0 0}$ \\
\hline \multicolumn{2}{|c|}{ Table 1. Age Distribution } \\
\hline
\end{tabular}

Maximum patients were (29\%) were between 41 to 50 years of age and least (20\%) between 51 to 60 years. Mean age was 40.3 years \{RANGE 20-60 years\}

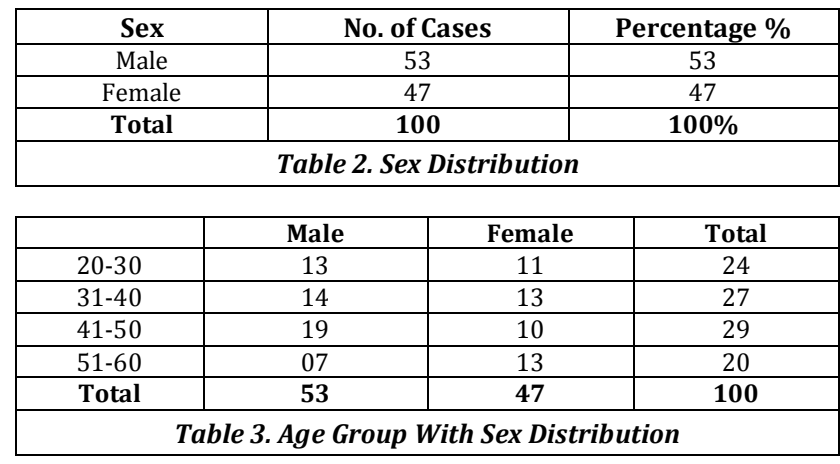

\begin{tabular}{|c|c|c|}
\hline Duration in Months & No. of Patients & Percentage \\
\hline $3-6$ & 39 & $39 \%$ \\
\hline $6-9$ & 31 & $31 \%$ \\
\hline $9-12$ & 19 & $19 \%$ \\
\hline $12-18$ & 6 & $6 \%$ \\
\hline$>18$ & 5 & $5 \%$ \\
\hline \multicolumn{2}{|c|}{ Table 4. Duration of Symptoms } \\
\hline Mean duration 4.3 \pm 0.788 months.
\end{tabular}

\begin{tabular}{|c|c|c|}
\hline Level & No. of Patients & Percentage \\
\hline L3 & 1 & $1 \%$ \\
\hline L4 & 6 & $6 \%$ \\
\hline L5 1 & 49 & $49 \%$ \\
\hline Total & 44 & $44 \%$ \\
\hline \multicolumn{2}{|c|}{ Table 5. Level of Injection } \\
\hline
\end{tabular}

\begin{tabular}{|c|c|c|}
\hline Side & No. of Patients & Percentage \% \\
\hline Right & 59 & $59 \%$ \\
\hline Left & 41 & $41 \%$ \\
\hline Total & $\mathbf{1 0 0}$ & $\mathbf{1 0 0}$ \\
\hline \multicolumn{2}{|c|}{ Table 5. Side Involvement }
\end{tabular}

In our study 59\% patients had radicular symptoms on Rt. Side and 41\% on left.

\begin{tabular}{|c|c|c|c|}
\hline \multirow{2}{*}{$\begin{array}{c}\text { Age Group } \\
\text { (Years) }\end{array}$} & Right & Left & \multirow{2}{*}{ Total } \\
\hline $20-30$ & 12 & 12 & 24 \\
\hline $31-40$ & 18 & 09 & 27 \\
\hline $41-50$ & 15 & 14 & 29 \\
\hline $51-60$ & 14 & 06 & 20 \\
\hline \multicolumn{3}{|c|}{ Table 6. Age Wise Side Involvement } \\
\hline
\end{tabular}

\begin{tabular}{|c|c|c|}
\hline & No. of patients & Percentage \\
\hline Central & 4 & $4 \%$ \\
\hline Lateral & 88 & $88 \%$ \\
\hline Far Lateral & 8 & $8 \%$ \\
\hline \multicolumn{3}{|c|}{ Table 7 } \\
\hline Total $100100 \%$
\end{tabular}

\begin{tabular}{|c|c|c|}
\hline Type of PIVD & No. of Patients & Percentage \\
\hline Bulge & 47 & $47 \%$ \\
\hline Protrusion & 45 & $45 \%$ \\
\hline Extrusion & 8 & $08 \%$ \\
\hline Total & $\mathbf{1 0 0}$ & $\mathbf{1 0 0} \%$ \\
\hline \multicolumn{3}{|c|}{ Table 8. Type of Disc Herniation } \\
\hline
\end{tabular}

\begin{tabular}{|c|c|c|c|}
\hline & Average & S.D. & N \\
\hline Pre injection SLR & 59.20 deg. & \pm 9.96 & $90 \mathrm{deg}$. \\
\hline Post injection SLR & $85.35 \mathrm{deg}$. & \pm 4.56 & $90 \mathrm{deg}$. \\
\hline \multicolumn{3}{|c|}{ Table 9. Straight Leg Raising Test Comparison } \\
\hline P-value $<0.001$
\end{tabular}

\begin{tabular}{|c|c|}
\hline & Mean \pm Standard Deviation \\
\hline Pre-injection & $5.98 \pm 1.359$ \\
\hline 1 Hour post injection & $2.20 \pm 1.312$ \\
\hline 1 Week post injection & $2.06 \pm 1.157$ \\
\hline 4 Weeks post injection & $1.87 \pm 1.236$ \\
\hline 6 months post injection & $2.25 \pm 1.316$ \\
\hline \multicolumn{2}{|c|}{ Table 10. Visual Analog Score } \\
\hline p-Vaue $<0.001$ \\
\hline
\end{tabular}

\begin{tabular}{|c|c|c|c|}
\hline Score & Disability & No. of Patients & Percentage \\
\hline $0-20$ & Minimal & 05 & $5 \%$ \\
\hline $21-40$ & Moderate & 77 & $77 \%$ \\
\hline $41-60$ & Severe & 12 & $12 \%$ \\
\hline $61-80$ & Crippling & 04 & $4 \%$ \\
\hline $81-100$ & Bed ridden & 02 & $2 \%$ \\
\hline \multicolumn{2}{|c|}{ Table 11. Oswestry Disability Index (Pre Treatment) } \\
\hline Most patients (77\%) in our study had moderate disability according to \\
Oswestry
\end{tabular}

\begin{tabular}{|c|c|}
\hline Oswestry Disability Index & Mean \pm Standard deviation \\
\hline Pre-injection & $32.95 \pm 8.26$ \\
\hline 1 Week & $11.91 \pm 4.75$ \\
\hline 4 Weeks & $12.03 \pm 4.65$ \\
\hline 6 Months & $15.63 \pm 5.03$ \\
\hline Table 12. Oswestry Disability Index Comparison \\
(Before and After Treatment)
\end{tabular}

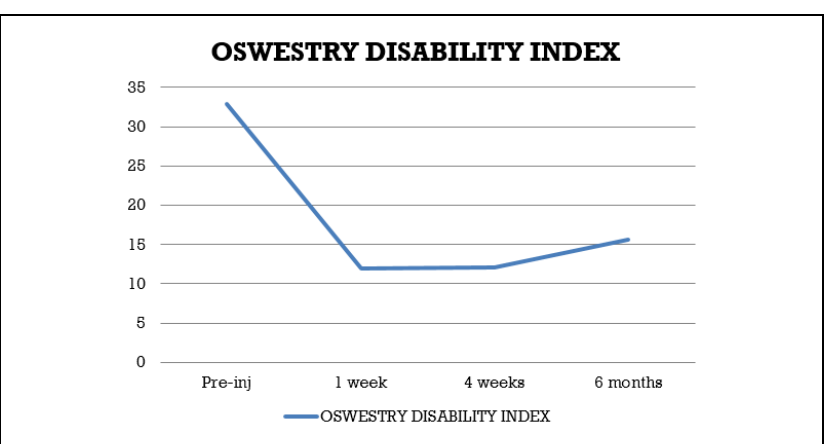

Figure 12. Oswestry Disability Index (Response to TFESI)

\begin{tabular}{|c|c|c|}
\hline Score & No. of Patients & Percentage \% \\
\hline Excellent & 63 & 63 \\
\hline Good & 33 & 33 \\
\hline Fair & 03 & 03 \\
\hline Poor & 01 & 01 \\
\hline Total & $\mathbf{1 0 0}$ & $\mathbf{1 0 0}$ \\
\hline \multicolumn{2}{|c|}{ Table 13. Modified McNab Scale } \\
\hline $\begin{array}{l}\text { On modified McNab scale, 63\% of patients had excellent score, 33\% good, } \\
\text { 3\% fair and 1\% poor score. }\end{array}$
\end{tabular}

\begin{tabular}{|c|c|c|}
\hline No. of Injections & No. of Patients & Percentage \\
\hline 1 & 88 & $88 \%$ \\
\hline 2 & 9 & $9 \%$ \\
\hline 3 & 3 & $3 \%$ \\
\hline Total & $\mathbf{1 0 0}$ & $\mathbf{1 0 0} \%$ \\
\hline \multicolumn{2}{|c|}{ Table 14. Patients Requiring Repeat Injections } \\
\hline
\end{tabular}

\begin{tabular}{|c|c|c|}
\hline Complication & No. of Patients & Percentage \\
\hline Vasovagal reaction & $\mathbf{4}$ & $\mathbf{4 \%}$ \\
\hline Disc entry & $\mathbf{3}$ & $\mathbf{3 \%}$ \\
\hline Intravascular entry & $\mathbf{3}$ & $\mathbf{3 \%}$ \\
\hline Neurodeficit & 1 & $1 \%$ \\
\hline \multicolumn{3}{|c|}{ Table 15. Complications } \\
\hline
\end{tabular}




\begin{tabular}{|c|c|c|c|}
\hline Gender & $\begin{array}{c}\text { Botwin et.al, } \\
\mathbf{2 0 0 2}\end{array}$ & $\begin{array}{c}\text { Hee Sun Jeong } \\
\text { et al, 200717 }\end{array}$ & Present Study \\
\hline Male \% & 53 & 46 & 59 \\
\hline Female \% & 47 & 54 & 41 \\
\hline \multicolumn{4}{|c|}{ Gender } \\
\hline Males constituted 59\% of our patients and females 41\%. These findings \\
are consistent with studies mentioned in the table. \\
\hline
\end{tabular}

\begin{tabular}{|c|c|c|c|}
\hline Level & Lutz et.al; 1998 & Ghahreman et al; 2010 & Present study \\
\hline L3 & 6 & 9 & 1 \\
\hline L4 & 12 & 12 & 5 \\
\hline L5 & 42 & 41 & 49 \\
\hline S1 & 40 & 38 & 44 \\
\hline \multicolumn{3}{|c|}{ Level of Injection } \\
\hline
\end{tabular}

\section{Follow Up and Assessment}

Follow up of patients was done at 1 weeks, 4 weeks, and 6 months after injection. At the first follow-up, if the patients benefit from their treatment, they were invited for formal follow-up. If patients felt that they had partial benefit, they were invited to have repeat of their allocated treatment in order to boost the response. Repeat injections, therefore, were given at the discretion of patients. If patient feels they had not benefited from treatment and need further treatment for their pain, they will be entitled to undergo rescue therapy. Rescue therapy could be analgesics or surgery

At each follow up patients were assessed for following-

- Pain relief in terms of VAS, requirement of analgesics.

- Ability to return to daily activities in terms of Oswestry Disability Index.

- $\quad$ Any queries.

- Any new symptoms.

- Patient satisfaction was assessed at last follow up in terms of Patient Satisfaction Index.

\section{DISCUSSION}

This prospective study was conducted on 100 patients attending to Postgraduate deptt. Of orhtopaedics, Hospital for bone and joint surgery, Barzulla, an associated hospital of Govt. Medical College, Srinagar. The study spanned over a period of 2 years. It evaluated the effect of epidural steroid, triamcinolone in our case, combined with local anaesthetic in patients with lumbosacral radiculopathy. The patients were selected according to the inclusion and exclusion criteriae laid down by this study.

Low back pain with radiculopathy is complex and linked to multifactorial spectrum of degenerative diseases of the spine. In most cases, episodes are self-limited and resolve with a passage of time, but for others it is recurrent, chronic which causes significant pain that interferes with smooth functioning of day to day chores. Treatment varies and may include conservative management, interventional procedures, and surgery. ${ }^{19}$

Most adult patients with low back pain and radicular pain improve with simple analgesics, sedatives, muscle relaxants and physiotherapy but a significant subset of patients continue to have chronic complaints that render them partially or completely disabled.20

A variety of therapeutic interventions are available to treat low back pain. These include spinal interventions such as Epidural Steroid Injections (ESI), zygapophysial joint intraarticular injections, nerve blocks, radiofrequency ablation, and spinal cord neuromodulation. ${ }^{21}$
The main objectives of interventional procedures are to improve pain and function so that the patient is able to participate in a comprehensive physical therapy program where any biomechanical deficiencies can be addressed. ${ }^{22}$

Although surgical decompression is successful when patients are properly selected but failure rate or only temporary relief is not uncommon. Recurrent pain in these patients is intractable and disabling, thus increasing the need of some effective alternative method of treatment. Surgery entails a high risk to patient and a high cost to society making a non-surgical therapeutic approach more desirable.

Injection of corticosteroids into the epidural space has long been used as a treatment for lumbosacral radicular pain due to disc herniation or degeneration. The basis for this treatment stems from evidence that suggests there is an increased production of pro-inflammatory mediators and cytokines because of disc herniation. ${ }^{23,24}$ This seems to be also the case in degenerative painful disc where there is the presence of higher levels of interleukin- 6 , interleukin-8 and prostaglandin E2.25,26,27, Introduction of corticosteroid into this space is believed to inhibit the inflammatory cascade and provide pain relief.

In our study on 100 patients of lumbosacral radiculopathy, the results were as follows; The mean age in our study was 40.3 years which is comparable to studies in the past (Taskaynatan et.al; 2015,28 Carette et.al, 199729)

Most (61\%) of our patients were non- sedentary workers while $39 \%$ were sedentary workers. These findings are consistent with the study by Clave and Galland (1930), who reported more incidence of LBA and radiculopathy in persons engaged in heavy work.

In $70 \%$ bending, in $49 \%$ walking, in $34 \%$ standing, in $19 \%$ coughing and sneezing, in $20 \%$ sitting, in $17 \%$ straining during stools and in $8 \%$ lying down increased the pain. It showed that physical activity was an important aggravating Peyton and Simmons (1947) ${ }^{30}$ where more than $70 \%$ of cases had aggravation of pain on bending and coughing.

The average pre injection SLR was $59.20^{\circ}$ which increased post injection to an average of $85.35^{\circ}$ (p-value<0.001) Standard deviation pre injection was 9.96 and after it was 4.56 . Hence there was statistically significant improvement in SLR.

The average duration of symptoms in our study was 4.13 months with standard deviation of 0.788 . Minimum duration was 3 months and maximum duration was 24 months. These findings are consistent with those of Vipul L. Kuvad (2015) ${ }^{31}$ who showed an average duration of 5.4 months and Simon Carette, 1997

In our study $59 \%$ of patients had right sided radicular symptoms and $41 \%$ had left sided symptoms.

Most of our patients (42\%) received L5 TFESI followed by S1 (40\%). Least commonly involved level was L3. These findings are comparable to the studies given in the table. Visual Analog Score In our study mean VAS before injection was 5.98 with S.D. of \pm 1.359 . After 1 hour of injection VAS dropped on average to $2.20 \pm 1.312$ (p-value $<0.001$ ). The mean drop in VAS continued through 7 days $(2.20 \pm 1.312)$ to 4 weeks $(1.87$ $\pm 1.236)$. The mean VAS showed some increase after 6 months $(2.25 \pm 1.316)$ but it was much lower than pre injection value and the difference was statistically significant ( $p$-value $<0.001$ ) 
The above findings confirm the effectiveness of TFESIs in properly selected patients and are consistent with findings of Vad VB et.al and Ahadian, Farshad et.al.

\section{Oswestry Disability Index}

Mean pre injection ODI was 32.95 (S.D. of 8.26). After TFESI it dropped to 11.91 at 1 week, 12.03 at 4 weeks and increased a bit to 15.63 with S.D. of 5.03. The change in ODI was statistically significant ( $\mathrm{p}$-value $<0.001$ ). Our study compares with that of Kawu et $\mathrm{al}^{32}$ (2012) who showed pre injection mean ODI of 31.2 and post injection of 12.2. Emre Adiguezel et al (2016) ${ }^{33}$ showed a mean pre injection ODI of 25 and 12.5 after 12 weeks. Hence TFESIs in properly selected patients can improve their engagement in day to day activities.

\section{Modified McNab Scale}

$63 \%$ of our patients had excellent outcome, $33 \%$ had good, $3 \%$ had fair and $1 \%$ had poor outcome as measured by this scale.

\section{Complications}

We encountered few complications during our study which are as follows- vasovagal reaction in $4 \%$ patients, disc entry in $3 \%$, intravascular entry in $3 \%$, neuro-deficit in $1 \%$, vasovagal reaction.

$4 \%$ of our patients suffered vasovagal reactions, all during the procedure. The reaction was diagnosed as a fall in BP with pt. complaining of dizziness. It was managed by IV fluids and all patients. This observation is in consonance with that of David J. Kennedy ${ }^{34}$ (2013) who reported an incidence of 3.6\% of vasovagal reaction in his study. Another study done by Karaman et $\mathrm{al}^{35}$, showed incidence of this complication to be $8.7 \%$.

We encountered disc entry in $3 \%$ of patients which was diagnosed by spread of dye into the disc space. The results did not vary in these patients and they had no additional complaint after the procedure. Hong et.al; (2013) ${ }^{35}$ reported the incidence of this complication to be $2.4 \%$. Candido et al; $(2010)^{36}$ reported its incidence to be $0.25 \%$.

Recognised by "flash back" or aspiration of blood, we met this complication in $3 \%$ of patients. The dye was, however, injected after withdrawing the needle few millimeters and reaspiration. None of our patients developed systemic effects of this complication. Furman et al; (2000) ${ }^{37}$ reported this complication in $11.2 \%$ patients. Karaman $\mathrm{H}$ etal, 38 reported in $7.4 \%$ of cases.

One of our patients developed L5 motor weakness after the procedure (grade 3/5). He however regained his power during the course of follow up without specific intervention. Bogduk et al; (2004) ${ }^{39}$ reported this complication without mentioning the percentage.

\section{CONCLUSIONS}

Transforaminal epidural steroid injection is an effective alternative method of pain control with improvement in disability with excellent patient satisfaction in properly selected patients of lumbosacral radiculopathy. However longer studies are needed to establish its long-term outcome.

\section{REFERENCES}

[1] Frymoyer JW, Cats-Baril WL. An overview of the incidences and costs of low back pain. Orthop Clin North Am 1991;22(2):263-71.
[2] Vad VB, Bhat AL, Lutz GE, et al. Transforaminal epidural steroid injection in lumbosacral radiculopathy: a prospective randomized study. Spine 2002;27(1):11-6.

[3] Silbergleit R, Mehta BA, Sanders WP, et al. Imagingguided injection techniques with fluoroscopy and CT for spinal pain management. Radiographics 2001;21(4):927-42.

[4] McLain RF. Lumbar disc disease. In: Frymoyer JW, Wiesel SW, eds. The adult and pediatric spine. $3^{\text {rd }}$ edn. Philadelphia, Pa: Lippincott Williams and Wilkins 2004: p. 929-44.

[5] Tong HC, Williams JC, Haig AJ, et al. Predicting outcomes of transforaminal epidural injections for sciatica. Spine J 2003;3(6):430-4.

[6] Cyteval C, Fescquet N, Thomas E, et al. Predictive factors of efficacy of periradicular corticosteroid injections for lumbar radiculopathy. Am J Neuroradiol 2006;27(5):978-82.

[7] Mixter JW, Barr JS. Rupture of intervertebral disc with involvement of spinal canal. $\mathrm{N}$ Engl J Med 1934;211:210-15.

[8] Sitzman BT. Epidural injection. In: Fenton DS, Czervionke LF, eds. Image guided spine intervention. Philadelphia: Saunders 2003: p. 99-126.

[9] Manchikanti L. Transforaminal lumbar epidural steroid injections. Pain Physician 2000;3(4):374-98.

[10] Fenton DS, Czervionke LF. Selective nerve root block. In: Image-guided spine intervention. Philadelphia, $\mathrm{Pa}$ : Saunders 2003: p. 73-98.

[11] Bogduk N. Lumbar transforaminal injection of rancisco, California: International Spine Intervention Society, 2004: p. 163-87.

[12] Sitzman BT. Epidural injection. In: Image-Guided Spine Intervention. Philadelphia: Saunders 2003: p. 99-126.

[13] Gajraj NM. Selective nerve root blocks for low back pain and radiculopathy. Reg Anesth Pain Med 2004;29(3):243-56.

[14] Liu SS, Melmed AP, Klos JW, et al. Prospective experience with a 20-gauge Tuohy needle for lumbar epidural steroid injections: Is confirmation with fluoroscopy necessary? Reg Anesth Pain Med 2001;26(2):143-6.

[15] McLain RF, Kapural L, Mekhail NA. Epidural steroid therapy for back and leg pain: mechanisms of action and efficacy. Spine J 2005;5(2):191-201.

[16] Botwin KP, Gruber RD, Bouchlas CG, et al. Fluoroscopically guided lumbar transforaminal epidural steroid injections in degenerative lumbar stenosis: an outcome study. Am J Phys Med Rehabil 2002;81(12):898-905.

[17] Jeoung HS, Lee JW, Kim SH, et al. effectiveness of transforaminal epidural steroid injection by using a preganglionic approach: a prospective randomized controlled study. Radiology 2007;245(2):584-90.

[18] Ghahreman A, Ferch R, Bogduk N. The efficacy of transforaminal injection of steroids for the treatment of lumbar radicular pain. Pain Medicine 2010;11(8):1149-68.

[19] Koc Z, Ozcakir S, Sivrioglu K, et al. Effectiveness of physical therapy and epidural steroid injections in lumbar spinal stenosis. Spine (Phila 1976) 2009;34(10):985-9. 
[20] Luijsterburg PA, Verhagen AP, Ostelo RW, et al. Effectiveness of conservative treatments for lumbosacral radicular syndrome: a systemic review. Eur Spine J 2007;16(7):881-99.

[21] Cyriax JH. Cervical disc herniation. Textbook of Orthopaedic Medicine. $3^{\text {rd }}$ edn. London: Cassell Publishing Company 1957: p. 460-9.

[22] Lindahl O, Rexed B. Histological changes in spinal nerve roots of operated cases of sciatica. Acta Orthop Scand 1951;20(3):215-25.

[23] Winnie AP, Hartman JT, Meyers HL, et al. Intradural and extradural corticosteroid injections in the management of low back ache. Anaesth Analg 1972;51(6):990-9.

[24] Dilke TFW, Burry HC, Grahame R. Extradural corticosteroid injection in management of lumbar nerve root compression. Br Med J 1973;2(5867):635-7.

[25] Brown FW. Management of diskogenic pain using epidural and intrathecal steroids. Clin Orthopaedics and Related Research 1977;(129):72-8.

[26] Heyse-Moore GH. A rational approach to the use of epidural medication in the treatment of sciatic pain. Acta-Orthop Scand 1978;49(4):366-70.

[27] Thomas DJ, John CR, Harold C, et al. Epidural steroid effect on nerves and meninges. Anaesthesia and Analgesia 1980;59(8):610-14.

[28] Taskaynatan MA, Tezel K, Yavuz F, et al. The effectiveness of transforaminal epidural steroid injection in patients with radicular low back pain due to lumbar disc herniation two years after treatment. J Back Masculoskelet Rehabil 2015;28(3):447-51.

[29] Carette S, Leclaire R, Marcoux S, et al. Epidural corticosteroid injections for sciatica due to herniated nucleus pulposus. N Engl J Med 1997;336(23):1634-40.

[30] Peyton WT, Simmons DR. Herniated intervertebral disk -analysis of 90 cases. Arch Surg 1947;55(3):271-87.
[31] Kuvad VL. A study of transforaminal epidural steroid injections in patients with lumbar disc herniation. Int J Res Med Sci 2015;3(12):3853-7.

[32] Kawu AA. Epidural steroid injection in patients with lumbosacral radiculopathy in Abuja, Nigeria. J Neurosci Rural Pract 2012;3(2):121-5.

[33] Adiguzel E, Tecer D, Guzelkucuk U, et al. The effectiveness of transforaminal epidural steroid injection in patients with radicular low back pain: combination of pain provocation with effectiveness results. Turk J Phys Med Rehabil 2017;63(2):117-23.

[34] Kennedy DJ, Schneider B, Casey E, et al. Vasovagal rates in fluoroscopy guided interventional procedures: a study of over 8,000 injections. Pain Med 2013;14(12):1854-9.

[35] Hong JH, Kim SY, Huh B, et al. Analysis of inadvertent intradiscal and intravascular injection during lumbar transforaminal epidural steroid injections: a prospective study. Reg Anesth Pain Med 2013;38(6);520-5.

[36] Candido KD, Katz JA, Chinthagada M, et al. Incidence of intradiscal injection during lumbar fluoroscopically guided transforaminal and interlaminar epidural steroid injection. Anesth Analg 2010;110(5):1464-7.

[37] Furman MB, O’Brien M, Zgleszewski TM. Incidence of intravascular penetration in transforaminal lumbosacral epidural steroid injections. Spine 2000;25(20):2628-32.

[38] Karaman H, Kavak GO, Tufek A, et al. The complications of transforaminal lumbar epidural steroid injections. Spine (Phila Pa1976) 2011;36(13):E819E24.

[39] Bogduk N. Clinical anatomy of the lumbar spine and sacrum. $4^{\text {th }}$ edn. London: Churchill Livingstone 2005. 